\title{
Canadian Physicians' Breach of Duty to Patients and Communities from the Acquisition of Indigenous Skulls in the 19th Century to the Abandonment of People with AIDS in the 20th Century
}

\author{
Philip Berger, M.D.
}

The impact of the Vienna Protocol transcends the world of Jewish law and provides important ethical considerations for modern medicine. This article provides a series of examples demonstrating how Canadian medical history intersects with the Vienna Protocol, and why historical insight remains relevant. Investigations into this exploitation include this author's own inquiry and attempt to repatriate Canadian indigenous skulls (a gift from William Osler to Rudolf Virchow), the glaring maltreatment of Aboriginal children in Canadian nutrition experiments, and the maltreatment of Canadian AIDS patients in the 1980s.

OPEN ACCESS

Thank you for inviting me to give a brief commentary. I am in an unusual position because I was asked to respond from the narrowness of the Canadian terrain, and somehow make what at first glance appears to be an unlikely connection to the lessons arising from Pernkopf's atlas. But four of this morning's speakers - Doctors Hildebrandt, Seidelman and Mackinnon, and Rabbi Polak, co-authored a surgical case history in the journal, Surgery, in which they admonished readers to, and I quote "...transcend the impact of the Vienna Protocol beyond the world of Jewish law into all contexts of modern medicine" (Yee, Zubovic, Yu, et al. 2019). The authors continued, "At the centre are self-restraint of the physician's choice, historic insight, and recognition of the humanity of the subjects in the images as well as of the patient to be treated." Canadian medicine is not free of the need for such historic insight.
Canadian born and trained Sir William Osler (1849-1919)

is widely regarded as one of the most influential physicians of the late 19th and early 20th century and a key figure in the history of medicine. Osler's greatest contribution to the medical world has been the system of residency, which he developed at the Johns Hopkins Hospital in Baltimore where he was one of the hospital's four founding professors. He has frequently been described as the Father of Modern Medicine and one of the "greatest diagnosticians ever to wield a stethoscope." Following post-graduate training under the famed German physician Rudolf Virchow, known as "the father of modern pathology" and as the founder of social medicine, Osler returned to the McGill University, Faculty of Medicine, as a professor in 1874. In 1905, he was appointed to the Regius Chair of Medicine at Oxford, which he held until his death. Many current Canadian institutions bear his name.

Dr. Harvey Cushing was a former student and close friend of Osler's and a pioneer of neurosurgery in the United States, who has himself become an icon of modern medicine. In 1925 Dr. Cushing published a monumental biography of Dr. Osler, which earned Cushing the Pulitzer Prize in 1926.

So, how do three of the most prominent physicians in medical history intersect with Canada and the Vienna Protocol (Polak, 2017)? Well, by pure coincidence I was sent copies of pages 212 to 214 of the Cushing biography of Osler. Cushing reproduces a letter from Osler, penned in May 1884, in which Osler references a gift he presented to Dr. Rudolf Virchow during a visit to Berlin. The gift, to quote Dr. Osler, was, "...four choice skulls of North American Indians," and according to Cushing, skulls which came from British Columbia. 


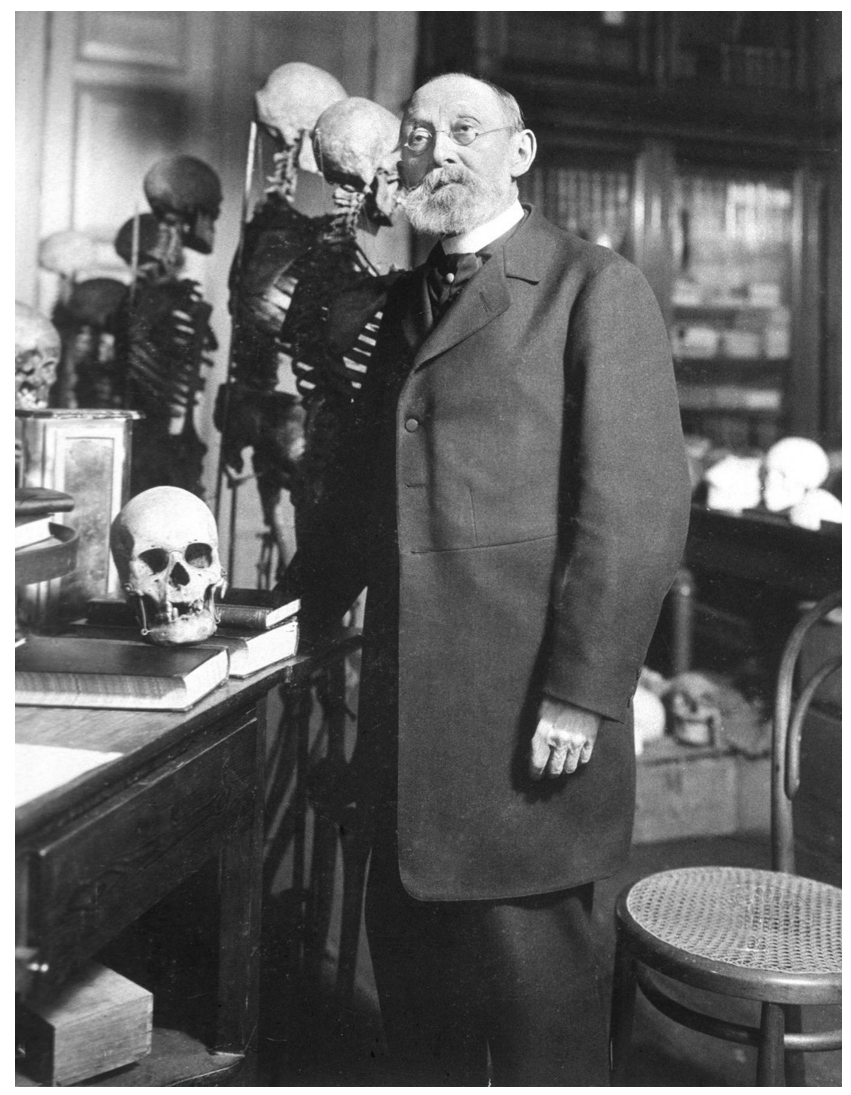

Dr. Rudolf Virchow pictured with his extensive skull collection. Photo credit: Rudolf Virchow photo provided by and licensed from Alamy Inc., Brooklyn, NY.

Thereafter began a now one-year quest to confirm the existence and location of the skulls. A junior colleague, Dr. Nav Persaud, joined me, and after approval and consultation with two Indigenous colleagues and an Indigenous law professor, and with the assistance of experts overseas, we determined that the skulls must be amongst the 4000 skull Virchow collection housed in the Berlin BGAEU museum (Berliner Gesellschaft Fur Anthropologie, Ethnologie und Urgeschichte). Despite four months of correspondence with the BGAEU, the final answer was that, "It will take time," for the BGAEU anthropologist to investigate the matter and that, "She will come back on you as soon as she finds time." That was last March.

We cannot secure a simple confirmation that the BGAEU possesses the skulls. This, despite a 2013 German Museums Association document entitled, "Recommendations for the Care of Human Remains in Museums and Collections," which calls for museums to have a "complete and standardized inventory system" (German Museums Association, 2013).
Our intention, had we been successful, was to pass the information on to Indigenous leaders, as naturally, issues arise of identification, descendants and repatriation - that is the domain of the First Nations from which the skulls were taken. So even today, and despite the lessons of Pernkopf and The Vienna Protocol supplement on Bone Finds, a German Museum cannot even move to the first step of answering a legitimate inquiry.

The Canadian medical profession, though producing no Pernkopfs, does carry the stain of exploitation and maltreatment of powerless groups. In 2013, food historian Ian Mosby at Guelph University published an exposé of nutrition experiments conducted between 1942 and 1952 on Canadian Aboriginal children at six residential schools (Mosby, 2013). Led by Dr. Percy Moore, then Indian Affairs Branch Superintendent of Medical Services and Dr. Frederick Tisdall, a renowned Hospital for Sick Children paediatrician and co-developer of baby Pablum, they studied malnourished Aboriginal children, divided into control and treatment groups, with neither receiving sufficient nutrition and absent of any parental informed consent. Children became sicker in both groups, partly because the researchers tried to control for confounding factors, thus in one instance denying dental care in order to study dental disease in malnourished children. Many experts hold that these experiments led to more deaths and delayed development of the children.

In the late 1980s word leaked out that Canadian Immigration doctors were administering powerful injectable sedatives to persons about to be deported from Canada. The purpose was to quell any resistance from the deportees and to ease the work of enforcement officers. An interfaith group of refugee advocates arranged for an independent doctor to examine a jailed person facing imminent deportation and ascertain that no medical indication existed to justify a sedative injection. The Globe and Mail reported the incident and followed up with an editorial condemning the practice, which soon ceased. Here we have doctors using their medical expertise solely to enforce the policies of the state and their colleagues intervening to stop it.

At the same time deportees were being drugged in Canada, the AIDS epidemic was exploding. "We...will not endure these waves of dying friends, without a cry," Canadian AIDS activist, Professor Michael Lynch, wrote in his 1989 poem, "Cry," as young men were "dying in waves," including Michael himself at age 46. 
In Toronto, a small group of downtown primary care physicians were overwhelmed with ailing people suffering life threatening, ferocious illnesses.

Part of the reason for the location of so many sick people into a few medical practices was because the regular doctors of these men kicked them out of their practices as soon as an HIV or AIDS diagnosis was made. The AIDS doctors referred to it as "doctor dumping". A JAMA (Journal of the American Medical Association) commentary in October 1987 by the eminent American researcher, Dr. Bruce Dan, referred to it as "Patients Without Physicians: The New Risk of AIDS" (Dan, 1987).

Though not of the order of unauthorized research or knowledge gained from the corpses of atrocity victims, doctors who abandoned AIDS patients breached their moral and ethical duty to use their expertise to support the sick - a small historical overlap between the AIDS epidemic and the Holocaust. Amongst the AIDS doctors in the USA, and I suspect also in Canada, Jews, gay men, lesbians, and leftists were massively overrepresented the very same groups targeted by the Nazi regime.

\section{Dedication}

In remembrance of the Indigenous children who did not survive Canadian residential schools, and in alliance with those who did survive and their families and communities.

\section{Author's Note - July 2021}

Two of the North American Indian skulls from the Virchow collection housed in the Berlin BGAEU Museum (Berliner Gesellschaft Fur Anthropologie, Ethnologie und Urgeschichte) have now been located.

The disposition of these skulls and whether they will be repatriated to the Indigenous peoples in Canada (First Nations) is still unknown at this time.

\section{References}

Dan, B.B. Patients Without Physicians: The New Risk of AIDS. JAMA. 1987;258(14):1940. doi:10.1001/jama.1987.03400140102037
German Museums Association, Human Remains Working Group. 2013. Recommendations for the Care of Human Remains in Museums and Collections. Access at: http://www.concernedhistorians.org/content files/file/TO /296.pdf

Mosby, I. Administering colonial science: Nutrition research and human biomedical experimentation in Aboriginal communities and residential schools, 19421952. Social History. 2013;46:145-72.

Polak, J.A. 2017. Vienna Protocol for When Jewish or Possibly-Jewish Human Remains are Discovered. In: Seidelman, W.E., Elbaum, L., Hildebrandt, S. (Eds.), How to Deal With Holocaust Era Human Remains: Recommendations Arising From a Special Symposium. Elie Wiesel Center for Jewish Studies, Boston University, Boston, MA. Accessed at: http://www.bu.edu/jewishstudies/files/2018/08/HOWTO-DEAL-WITH-HOLOCAUST-ERAREMAINS.FINAL .pdf

Yee, Andrew, Zubovic, Ema, Yu, Jennifer, Ray, Shuddhadeb, Hildebrandt, Sabine, Seidelman, William E., Polak, Joseph A., Grodin, Michael A. J., Coert, Henk, Brown, Douglas, Kodner, Ira J., Mackinnon, Susan E. 2019. Ethical considerations in the use of Pernkopf's atlas of anatomy: A surgical case study. Surgery. 165(5), 860-867. Access at: https://doi.org/10.1016/j.surg2018.07.025 or https://www.sciencedirect.com/science/article/abs/pii/S00 39606018304811
About the Author
Dr. Philip Berger is an Associate Professor at the University of Toronto. He was Medical Director of the Inner City Health Program at St. Michael's Hospital, Toronto from 1997-2017 and former Chief of the Department of Family and Community Medicine from 1997 to 2013. Dr. Berger has helped establish human rights related health organizations arising from his work with torture victims, refugees and people with HIV and has been involved in campaigns to fight poverty and to support drug users. He is a co-founder and is a Special Advisor to Canadian Doctors for Protection from Guns. Throughout his 40-year career he has been an advocate and champion of social and political change in health care. In 2018 Dr. Berger was inducted into the Canadian Medical Hall of Fame. In 2020 Dr. Berger received the Order of Canada. 


\section{Philip Berger, M.D.}

St. Michael's Hospital and the

Department of Family and Community Medicine

Temerty Faculty of Medicine, University of Toronto

Contact:philip.b.berger@gmail.com

\section{Licensing}

The author has chosen to license this content under a Creative Commons Attribution, NonCommercial, NoDerivatives 4.0 International License.

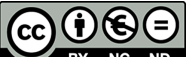

\section{Image Credit}

The photo of Dr. Rudolf Virchow was provided by, and licensed from, Alamy Inc., Brooklyn, NY.

\section{Conflict of Interest Statement}

The Journal of Biocommunication Management Board and Editors believe that transparency in academic research is essential. Our JBC authors are now required to disclose any possible conflict of interest when submitting a manuscript. In accordance with the Journal of Biocommunication's editorial policy, no potential conflict of interest has been reported or declared by this author. 